\title{
knashibiber \\ Massages in the library \\ Running a course design spa for faculty
}

A

sk any faculty member about their biggest challenge today, and many of them will say, "There's never enough time!" Studies have shown that faculty work longer hours than their predecessors, and feel stress from their workloads. ${ }^{1}$ While librarians and other campus support staff are eager to sit down with faculty and talk about resources or offer help designing assignments, unfortunately many faculty feel pulled in so many directions that they don't make time to seek help from campus support offices.

To combat this, librarians, instructional technologists, and teaching center staff at Emerson College designed an event to give them the gift of time-and a massage. This article will outline how we organized a Course Design Spa, allowing faculty to spend a day "rejuvenating" their courses while working with librarians and other campus support staff to improve various aspects of their assignments, syllabi, and teaching.

\section{Program design}

The Course Design Spa is a one-day event held in the library one week before classes begin in the Fall and Spring semesters. "Consultants" from various support offices (library, teaching center, IT, disability services, counseling center, writing center, diversity office, etc.) around campus offer their time to meet with faculty during the spa. Faculty are invited to work on any aspects of their courses, and can sign up for "Treatments" with the consultants throughout the day. Lunch is provided. Participation is limited to 30 faculty to ensure access to the consultants.

\section{Planning}

The idea for the spa grew out of conversations between librarians, instructional technologists, and campus teaching center staff in summer 2013. We were looking for an event that would allow us to join forces to support our campus faculty. Knowing many faculty feel very busy, we wanted an event that would catch their eye. While most people wouldn't be excited about spending a day prepping class materials, who wouldn't want to spend a day at a spa?

For structure of the Course Design Spa, we decided to model it after a faculty Writers' Retreat the library had recently offered. During the Writers' Retreat, the librarians offered very few mandatory activities. The main draw for faculty was that it was a solid chunk of time to work on their writing projects.

Beyond being appealing to faculty, this unstructured aspect also made for much easier planning. We didn't need to guess which activities faculty would need, or when. Instead we designed a day where faculty were allowed to structure their own time, and could sign up for individual appointments with "Consultants" throughout

Karla Fribley is instruction coordinator and reference librarian at Emerson College, email: karla_fribley@ emerson.edu

() 2015 Karla Fribley 
the day. And of course, because we were billing it as a spa day, we hired licensed massage therapists to come in and offer chair massages throughout the day.

We asked faculty to complete a registration form describing the course design project(s) they'd be working on, and which type(s) of help they might want from consultants. This helped us figure out how much demand there might be for a particular consultant, and allowed the consultants to prepare for some of the questions beforehand. Knowing that a lot of our departmental names are mysterious to users ("How does Instructional Technology differ
Based on pre-registration, we knew there would be heavier demand for some services than others. We decided to have a master schedule that faculty would use to sign-up for their individual appointments with consultants. While we considered an online scheduling tool, we eventually opted for a lower-tech version by creating the schedule on a large movable whiteboard.

At the start of the day, after hearing introductions from all the consultants regarding their areas of expertise, faculty are able to sign up for consultations by adding their name to an appointment slot for that consultant.

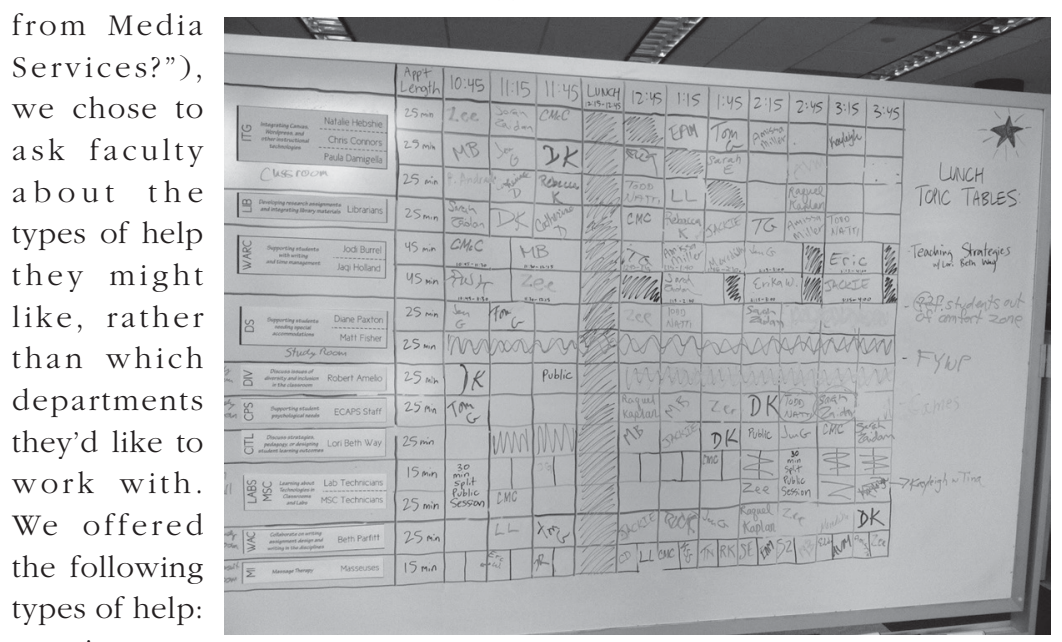

- integrate instructional technologies

Image of whiteboard used for consultation sign-ups. View this article online for detailed image.

\section{Promotion}

For our first version of the spa, we discussed different types of outreach, but quickly found we didn't need to do much promotion. We sent out a single email announcement to all faculty, and found we had a waitlist before the week was over. For each subsequent version, we have always had a waitlist, with very minimal advertising.

During the Course Design Spa, we provide faculty with a tongue-in-cheek "Spa Services" brochure that highlights the kinds of help faculty can receive, including the following:

- Assignment Exfoliation: Librarians from the Iwasaki Library will work with you to redesign old and new research assignments, bringing out their natural shine. Librarians can consult with you on designing research assignments, information literacy, and library resources for your course. 
- Reflexology: Consultants from the Writing and Academic Resource Center are available to talk about student trouble zones and ways to apply therapeutic pressure for writing, study, and time management skills. Concentrating on student troublespots in one area often has mirrored benefits in other areas. Also, identify and relieve troublespots with writing assignments.

We have had concerns that we go a bit over the top with the spa theme, but have found faculty genuinely embrace all the details.

\section{Funding}

Each sponsoring department (library, instructional technology, and teaching center) contributes $\$ 300$, creating a budget of $\$ 900$. The two licensed massage therapists charge $\$ 300$ for the day, and lunch and coffee cost $\$ 600$. Because we host the event in the library, we do not have any expenses for the location.

\section{Participant feedback}

The Course Design Spa has been a huge hit, both for faculty and the participating support staff that work as consultants. For faculty, they appreciate the concentrated chunk of time to work on their course projects, the chance to work with other faculty, and all of the available help from consultants. We've found the average faculty member signs up for four different treatments throughout their day.

One wonderful part of this is that a faculty member often ends up getting help in areas they hadn't anticipated. For example, a faculty member might plan to come in and work with the instructional technologists about integrating a blog into his or her course, but also end up talking with a librarian about designing a research assignment, or to disability services about how to support a student needing accommodations.

For consultants, they found the opportunity to engage with faculty in meaningful ways, often spending 30 to 45 minutes in one-on-one conversations. In some cases it provides a chance to put a face to a name, or to work with a frequent collaborator, but in many other cases, consultants find themselves working with faculty they've never connected with before.

Beyond informal feedback, we ask participants and consultants to complete a post-spa feedback form. For participants, we ask them to give feedback on their interactions with fellow participants and consultants, and also to comment on the progress they made during the spa so we have a sense of what they accomplished during the day. This final piece gives us evidence of impact beyond some of the affective or satisfaction-based feedback ("Great day!"). For consultants, we ask them to count the number of faculty they helped, the kinds of questions they answered, what surprised them, and what they would change for next time.

\section{Lessons learned}

Throughout the various versions of the spa, we've made changes based on participant feedback and our observations.

In our first version of the spa, librarians decided to offer "drop-in" help for any questions in lieu of booking appointments with faculty. We reasoned that since the reference desk was close to the location of the event, we could staff that desk and just answer questions informally. Unfortunately we found this led to fewer consultations with faculty than we would have liked. For subsequent versions, we have asked faculty to sign up for appointment slots, and found this increased the number of consultations. Our speculation is that signing up and committing to an actual time slot increases the likelihood that faculty will follow through with investigating an interest area.

We've also found it helps to proactively encourage faculty to sign up for consultations. If we notice that someone indicated in their pre-registration that they'd like to speak with a librarian, but we don't see them sign up for an appointment, we reach 
out to them during the day to see if they still have any questions. Similarly, if there are faculty in attendance with whom we'd like to collaborate, but who haven't signed up for a librarian consultation, we seek them out during the day and encourage them to sign up for one.

One thing we often hear from faculty participants is that while they love the oneon-one conversations with the consultants, they'd also like more opportunities to talk more with other faculty. We've tried several different ways to increase these types of interactions. In early versions of spa, we didn't set a specific lunchtime, and instead allowed participants to decide individually when they would like to break for lunch.

However in subsequent versions we've found setting a specific lunch break, with no consultations offered during that break time, helped increase group interactions. Less successfully, we once tried suggesting that faculty organize themselves into "Topic Tables" at lunch, but found few took advantage of these formal groupings.

Beyond lunches, we've experimented with changing some of the individual consultation slots into group sessions. Some treatments lend themselves especially well to group conversations, such as talking about issues of diversity in the classroom, or talking about pedagogy. We offered nine of these public sessions at our most recent version, and received positive feedback. Faculty appreciate the chance to learn from other faculty, in addition to the staff moderator. We will be experimenting more with these in the future.

One consistent piece of feedback that we have not yet resolved involves the method of signing up for treatments. We have opted to have faculty sign up for their treatments on a large whiteboard on the day of the workshop, after they've heard introductions from all the consultants. We've chosen this method because it doesn't involve training anyone how to use software, doesn't require that everyone have a computer, encourages faculty to lis- ten to all the consultants introductions and then decide their interest areas, and avoids the issue of someone signing up for many appointments in advance, only to change plans on the day of the spa.

Unfortunately, this method does lead to somewhat of a "crush" at the start of the day when everyone swarms the whiteboard to sign up for their appointments at once. While no fistfights have ever broken out, some participants have grumbled about the "assertiveness" some of their colleagues have exhibited in maneuvering towards the whiteboard. For future versions, we may experiment with an online method of signing up for appointments with consultants in advance of the spa.

\section{Conclusion}

Overall the Course Design Spa has proved a popular event for both faculty and consultants. For a daylong program, the costs are low, and the response is strong. For libraries looking to heed the call of the 2011 ACRL Standards for Libraries in Higher Education to "collaborate with campus partners to provide opportunities for faculty professional development," ${ }^{2}$ the Course Design Spa provides a successful model. The unstructured aspect of the day makes it easy for faculty to choose the help that interests them most, at the time that interests them. For the event planners, it provides an excellent opportunity to collaborate one-on-one with faculty on their courses. We'll continue offering the spa at the start of each semester as a light-hearted but effective way of bringing together campus support offices and faculty.

\section{Notes}

1. J. M. Gappa and A.E. Austin, "Rethinking Academic Traditions for Twenty-FirstCentury Faculty," AAUP Journal of Academic Freedom 1 (2010): 4-6. Accessed October 5, 2014, www.aaup.org/sites/default/files/files /JAF/2010\%20JAF/Gappa.pdf.

2. Standards for Libraries in Higher Education (Chicago: ACRL), 2011. $\boldsymbol{n}$ 